\title{
MOTIVAÇÕES E CIRCUNSTÂNCIAS QUE LEVAM A NÃo USOS DOS MÉDIA POR JOVENS E SEUS FAMILIARES
}

\author{
Maria José Brites \& Cristina Ponte
}

\begin{abstract}
RESUMO
Neste artigo argumentamos pela necessidade de atenção a dinâmicas de recusa e de rejeição de utilização dos média para melhor se compreender a sociedade de consumo profundamente mediatizada. Seguimos um suporte teórico sobre resistência aos média, contextos familiares de socialização e sociedade mediatizada. Analisamos 18 entrevistas realizadas em Portugal - conduzidas no âmbito de uma investigação mais vasta com 40 jovens e seus familiares, sobre a sua relação com os média na perspetiva de direitos de cidadania -, que evidenciaram sinais de não uso dos média. O presente artigo caracteriza estas pessoas, os seus contextos e motivos. Identificando recusas da internet, das redes sociais, das notícias e da televisão, chegamos a cinco tipos: "Não gosto e não quero usar"; "Nesta fase da vida, não!"; "Entre o não posso ter e o não posso comprar"; "Não dar nas 'vistas' e não ficar 'agarrado'" e "Fazer diferente e fazer melhor".
\end{abstract}

\section{REASONS AND CIRCUMSTANCES THAT LEAD TO THE NON- USE OF MEDIA BY YOUNG PEOPLE AND THEIR FAMILIES}

\begin{abstract}
This article argues for the need to pay attention to the dynamics of refusing and rejecting the use of media to better understand a highly mediatized consumer society. The theoretical background utilizes resistance to the media, family contexts of socialisation and mediated society. We analysed 18 interviews carried out in Portugal - undertaken as part of wider research project involving 40 young people and their families, on their relationship with the media regarding citizenship rights -, which showed signs of non-use of media. This article characterises these individuals, their contexts and motives. Through identifying refusal of the internet, social networks, news and television, we arrive at distinct five types: "I do not like and I do not want to use"; "At this stage of life, no!"; "Split between I can't have and I can't buy it"; "I don't want to draw attention to myself and don't want to get 'hooked'"; and "Doing something different and doing it better".
\end{abstract}




\section{INTRODUÇÃo}

No início da década de 1960, quando o cartoonista Quino pensou a tira alusiva a Mafalda não ter televisão, estava longe de antecipar como essa tira viria a ser importante para refletir e parodiar a relação quase umbilical entre seres humanos e ecrãs. $O$ que estava implícito naquela tira era a opção de alguém, sagaz entre os pares, dizer não a uma cultura dominante. Mafalda não o fazia sozinha: crescia num ambiente familiar com essa opção.

As décadas passaram e à televisão vieram juntar-se novos ecrãs. Os média tornaram-se mais conectados, ubíquos, omnipresentes, com um ritmo acelerado de inovação: vivemos tempos de mediatização profunda (Couldry \& Hepp, 2017; Hepp \& Hasebrink, 2018). Sem dúvida que a permanente conexão mediada facilita relações e interações, pressupondo um valor societal fundamental (Livingstone, 2014). Mas a outra face merece igual atenção: quem não quer e quem não pode usufruir das condições proporcionadas por esse contexto.

Este artigo assenta na perspetiva de que é preciso perceber como se desenvolvem as desconetividades para entender a imersividade. Não basta olhar para os consumos, é preciso olhar também para os não consumos pois só o entendimento de ambos os lados - cada vez mais encarados em mobilidade (Araújo, Cogo \& Pinto, 2015) e como fluídos (Syvertsen, 2017) - permite conhecer a sociedade mediatizada (Woodstock, 2014). Se os contextos de exclusão associados a razões socioeconómicas têm sido explorados (Brites, 2015), procuramos também compreender melhor os ainda pouco estudados contextos de resistência e de autoexclusão (Neves \& Rente, 2017; Schrøder \& BlachØrsten, 2016).

Foram sinais de resistência e/ou de impossibilidade em usufruir dos média (televisão, internet, redes sociais) que conduziram à análise que está na base deste artigo. Entre as 40 entrevistas realizadas nos finais de 2015 e inícios de 2016 que tinham como objetivo apreciar como jovens e seus familiares adultos referiam a relação com os média na perspetiva de direitos de cidadania, encontramos em perto de metade, (18) casos, em que um dos membros do par familiar enunciava não fazer um dado uso e casos em que ambos eram consonantes nos meios de comunicação e conteúdos que diziam ignorar.

Antes de procurar sistematizar motivações e constrangimentos por detrás destes sinais de exclusão, importa ter presente o contexto mediático particular em que surgem estes dados. Em Portugal a chegada massiva dos média audiovisuais e digitais aos lares ocorreu mais tarde do que noutros países europeus e a televisão continua a ser o meio hegemónico e de maior vinculação (Burnay \& Ribeiro, 2016).

Se entre os internautas mais jovens (15-24 anos) o acesso à internet é quase universal, acima dessa idade, as diferenças são marcadas. Dados estatísticos do momento do estudo indicavam que mais de metade das mulheres (57\%) não usavam, enquanto nos homens essa fasquia não chegava à metade (43\%). O fosso geracional dava-se a partir dos 45-54 anos, com mais de metade a não fazer uso, e acentuava-se nas faixas etárias seguintes. Mais de dois terços dos que não ultrapassaram o ensino básico não faziam uso da internet, para $13 \%$ entre os que tinham $012 .^{\circ}$ ano e $7 \%$ entre os que possuíam ensino superior (INE, 2015). 
Por outro lado, a liderança dos internautas portugueses no uso de redes sociais destaca-se em termos europeus: mais de três quartos usavam-nas, acima da média europeia (57\%); $98 \%$ dos internautas portugueses que usavam redes sociais tinham um perfil na rede Facebook, com um número de "amigos" que ultrapassava as centenas na maioria (INE, 2015).

Relativamente ao consumo de notícias em Portugal, em 2016 o relatório do Reuters Institute (Newman, Fletcher, Kalogeropoulos, Levy \& Nielsen, 2017) indica que o país se situa próximo dos países do norte da Europa no que se refere à sua rejeição (22\%). É um valor bastante abaixo da Turquia, o país com mais rejeição (57\%). Os valores de rejeição apontados pelos portugueses estão também abaixo da média apurada naquele relatório, no qual quase metade (48\%) refere as notícias terem um efeito negativo no estado de espírito, seguindo-se a falta de confiança na sua veracidade (37\%). Segundo o relatório do OberCom (2017), associado ao estudo do Reuters Institute, entre as razões para os portugueses evitarem notícias estão o querer evitar influências negativas (37\%), o desgosto por algumas imagens (24\%) e o não confiarem nelas (20\%).

A estes contextos há que realçar que nos anos que antecederam a realização destas entrevistas, Portugal vivia uma severa crise económica, com famílias de todos os extratos sociais a experimentarem constrangimentos de vária ordem com possível impacto nas suas práticas com os média.

\section{PráticaS MEdiáticaS E dinÂMICAS FAMILIARES}

Começámos este texto recordando a diferença entre Mafalda e os seus pares no que se diz respeito à televisão e indicamos de passagem o ambiente familiar. Aprofundemos um pouco este ponto. Na consideração das dinâmicas familiares em processos de mediatização (Krotz, 2009) e de transmissão geracional (Buchner, 2003) são relevantes conceitos como capital cultural e distinção, de Bourdieu (2003), e os conceitos de configuração social e formação pessoal ou habitus, de Elias (1987). O conceito de capital cultural, em relação com outras formas de capital - social, educacional e económico - descreve as mudanças nas oportunidades de vida das pessoas geradas pelo desenvolvimento dos meios de comunicação. O conceito de configuração social - de que a família é exemplo recorrente - destaca interdependências entre membros que afetam as suas experiências e ações e que são também afetadas pelos seus contextos. Em interação com a família, a formação da personalidade ou habitus é o processo pelo qual o indivíduo vai correspondendo a normas específicas que estão definidas pelos membros dessa configuração.

Ainda que as famílias se tenham democratizado nas relações entre os seus membros (Beck, 1997; Beck \& Beck-Gernsheim, 2002) as relações familiares continuam a ser marcadas por expetativas parentais em proporcionar aos filhos certas trajetórias pessoais e sociais, sendo isso particularmente visível nas classes médias. A procura da distinção face a outras famílias e de acumulação de capital cultural marca o acesso a bens materiais e imateriais, como o conhecimento ou a educação formal. Buchner (2003) destaca as microculturas da família como espaços vitais para os seus membros, tanto no que se refere a oportunidades como a restrições. 
A relação de famílias com a televisão é ilustrativa destes processos. Tendo sido apropriada com entusiasmo pelas classes populares, suscitou reservas entre as elites que consideravam que os seus conteúdos não teriam qualidade suficiente e poderiam mesmo causar danos na educação das gerações mais novas. A recorrência de preocupações com conteúdos considerados violentos, inadequados ou nocivos para a democracia e para os mais novos tem pautado a história da televisão (Milner, 2002; Postman, 1985/2005; Putnam, 2000).

Também as notícias, sobretudo as de noticiários televisivos, suscitam por vezes resistência, rejeição ou desconsideração. Helgerud (2017) identifica três explicações para baixos níveis de interesse pelas notícias: desinteresse pelo seu conteúdo e forma; necessidade de prioritizar a gestão do tempo; evitar ou rejeitar notícias que deprimem, como assinalado nos estudos de Schrøder e BlachØrsten (2016) e Moeller (1999). Um ambiente social depressivo - crise económica, catástrofe - terá também impacto nas resistências e nas recusas. A saturação da própria informação pode ser outro fator.

Se o acompanhamento da atualidade tem uma raiz perene na relação de públicos com os média que aí procuravam informação adequada aos seus interesses - desde a leitura do jornal impresso pela manhã, como uma "missa" ao ritual do telejornal seguido em família, hoje esse acompanhamento faz-se pela conexão entre os média, com conteúdos atualizados e disponíveis em qualquer lugar.

Ao contrário da televisão, nos seus primeiros tempos a internet foi valorizada de uma forma celebratória (Castells, 2008; Jenkins, 2006). Com a web 2.0 as preocupações alastraram-se aos contactos proporcionados pelo meio e a conteúdos gerados por utilizadores. Poucos anos depois de terem surgido como comunidades de interesses, as redes sociais digitais entraram na lógica do desenvolvimento de conexões (Dijck, 2013). A pressão para a conexão tornou-se tão banal em aplicações móveis que muitos internautas ignoram a lógica de produção de valor económico que lhe está subjacente.

As preocupações em resistir às pressões da paisagem mediática são narrativas comuns a outros desafios políticos, sociais e culturais, considera Syvertsen (2017). Com um trabalho extensivo sobre resistência aos média, a autora aponta que esta é frequentemente ligada a uma conceptualização negativa, "vista como forma de pânico, como reação emocional causada pela tecnofobia, o medo, a histeria ou a marginalização social" (Syvertsen, 2017, p. 4). Contudo, a autora contrapõe a necessidade de considerar alguma forma de resistência como necessária num contexto de mediatização profunda: "numa era onde os meios estão por toda a parte, todos precisamos de uma dada resistência ou pelo menos de encontrar uma estratégia de autorregulação, para evitar que os média se tornem demasiado invasivos" (Syvertsen, 2017, p. 97).

Um recente estudo qualitativo sobre jovens adultos não utilizadores de sites de redes sociais (Neves \& Rente, 2017) destacou a diversidade de não usos, as suas contingências e a sua potencial transição. A partir de uma análise empírica as autoras elaboraram três tipos ideais deste não uso voluntário: o intencional, que inclui a opção deliberada pela exclusão; o imposto, que decorre de pressões experienciadas para essa exclusão; e o instrumental, que intercala o não uso com o uso para finalidades específicas. Esta 
tipologia vai também iluminar a análise sobre as formas de não uso a que este artigo se reporta.

Antes de vermos que tipos de resistências e a quê foram encontrados neste grupo de jovens e de adultos maduros reunidos por laços familiares, apresentamos a metodologia da análise realizada.

\section{Metodologia}

Como indicámos, na origem desta análise está uma amostra inicial de 40 indivíduos entrevistados entre novembro de 2015 e abril de 2016 sobre consumos de notícias e usos dos média, no âmbito de uma pesquisa de pós-doutoramento. Sendo um trabalho qualitativo e de caráter participativo, optamos por entrevistas-semiestruturadas e por indicar nomes fictícios, para manter anonimato e confidencialidade dos participantes. Para esta análise houve o cuidado, como se verifica na revisão de literatura, em apontar estudos posteriores que continuam a validar os dados de 2015-2016 e a dar relevância ao olhar sobre os resistentes aos média. Tendo em conta a crise económica e social (2011-2014) vivida no país, foi objetivo realizar a pesquisa em dois contextos socioeconómicos distintos: uma escola de classe média, que desenvolve um projeto de promoção da cidadania quotidiana, e um centro de apoio a jovens em risco de exclusão social. Em ambos os espaços, os jovens trariam um dos seus familiares para o estudo, se assim entendessem, o que não ocorreu em todos os casos. Quando realizadas ao par familiar, as entrevistas foram feitas em separado, permitindo cruzar informações.

$\mathrm{Na}$ transcrição das 40 entrevistas, encontramos falas que apontavam formas de resistência, rejeição e impossibilidade daqueles consumos, por parte de 18 entrevistados: sete jovens, cinco do sexo feminino e dois do sexo masculino; 11 adultos entre 45 e 61 anos, sete do sexo feminino e quatro do masculino. Não foram considerados neste grupo entrevistados que diziam gostar menos de algo (notícias, internet, redes sociais). Foram apenas considerados os que - claramente - resistiam, rejeitavam ou recusavam de forma ativa e para quem essas rejeições implicavam uma reflexão e gestão específica dos seus quotidianos. Se tivéssemos incluído os que indicavam gostar menos, o grupo seria um pouco maior, em especial no que respeita às notícias.

Para a análise, procedemos à codificação no NVivo 11.3.2 1888. Foram considerados temas relacionados com as recusas e resistências identificadas e a sua relação com a teoria. Baseamo-nos na grounded theory, deixando os dados falar por si, refletindo e abrindo novas pistas com a teorização (Seale, 2004), e na análise temática (Attride-Stirling, 2001), pois têm pontos em comum de organização da informação (Attride-Stirling, 2001; Corbin \& Strauss, 1990).

As categorias foram induzidas através dos dados (Amado, Costa \& Crsoé, 2014). Seguindo as indicações de Bardin (2009), primeiro reconhecemos as diferenciações e numa fase seguinte fomos reagrupando os elementos por grandes temas/categorias, que indicam as características comuns que as constituem. Alguns participantes estão inseridos em mais do que uma categoria, pois indicaram várias resistências ou rejeições. 


\section{ANÁLISE DOS RESULTADOS}

A rede social hegemónica Facebook é a que suscita mais resistência, sendo apontada por metade dos indivíduos do grupo e é transversal à idade. Por sua vez, a internet desmerece a atenção de cinco indivíduos, com a idade a ter um peso preponderante. $A$ televisão é desvalorizada por quatro, o telemóvel e certos conteúdos noticiosos por três.

Organizamos as respostas individuais e as ligadas a dinâmicas familiares em duas tabelas. Em cada uma apresenta-se o/a participante, a sua idade, escolaridade, aquilo que refere não fazer uso e como caracteriza, nas suas próprias palavras, o ambiente de acesso a informação em casa e os usos da internet. Vejamos a tabela sobre resistências manifestadas apenas individualmente.

\begin{tabular}{|c|c|c|c|c|c|}
\hline PARTICIPANTE & IDADE & $\begin{array}{l}\text { ESCOLARIDADE } \\
\text { E PROFISSÃo }\end{array}$ & $\begin{array}{l}\text { RESISTÊNCIA/ } \\
\text { REJEIÇÃo }\end{array}$ & Ambientes MEdiÁticos & USOS DA INTERNET \\
\hline Arminda & 59 & $\begin{array}{l}12^{\circ} \text { ano; } \\
\text { comercial }\end{array}$ & $\begin{array}{l}\text { Internet; "notí- } \\
\text { cias tristes" }\end{array}$ & $\begin{array}{l}\text { Muitos livros em casa, de } \\
\text { vários tipos, inclusive de arte. } \\
\text { Na televisão, gosta de ver } \\
\text { filmes e desenhos animados. }\end{array}$ & $\begin{array}{l}\text { Só usa a internet por obriga- } \\
\text { ção, no trabalho. Considera } \\
\text { ter boa memória para se } \\
\text { lembrar de tudo. Tem um } \\
\text { telemóvel sem internet. }\end{array}$ \\
\hline Antónia & 49 & $\begin{array}{l}4^{\circ} \text { ano; está refor- } \\
\text { mada (refeitório } \\
\text { e limpezas) e } \\
\text { faz limpezas }\end{array}$ & Facebook; internet & $\begin{array}{l}\text { Em casa, o computador } \\
\text { avariou e não pôde arranjar } \\
\text { por falta de dinheiro; tem } \\
\text { telemóvel sem internet; por } \\
\text { vezes tem acesso ao Jornal } \\
\text { de Notícias impresso. Vê } \\
\text { notícias na TV, que consi- } \\
\text { dera uma companhia. }\end{array}$ & $\begin{array}{l}\text { Usa por vezes no tablet } \\
\text { do neto, sobretudo para } \\
\text { ver quais são os amigos } \\
\text { homens que ele tem online } \\
\text { (receio da pedofilia); pede } \\
\text { ao neto para Ihe mostrar e } \\
\text { ele fá-lo, sem questionar o } \\
\text { que lhe está a ser pedido. }\end{array}$ \\
\hline Filipe & 45 & $\begin{array}{l}12^{\circ} \text { ano; técnico } \\
\text { na CMP }\end{array}$ & Facebook & $\begin{array}{l}\text { Em casa tem televisor e } \\
\text { livros escolares. Costuma } \\
\text { ler jornais desportivos. Usa } \\
\text { a internet no emprego e em } \\
\text { casa, para ver as notícias. }\end{array}$ & $\begin{array}{l}\text { Usa para ver notícias } \\
\text { e entretenimento. }\end{array}$ \\
\hline Romeu & 47 & $\begin{array}{l}\text { Doutoramen- } \\
\text { to; professor } \\
\text { universitário }\end{array}$ & $\begin{array}{l}\text { Facebook; "notícias } \\
\text { de política" }\end{array}$ & $\begin{array}{l}\text { Em casa, há televisão, livros, } \\
\text { CDs, DVDs, jogos digitais; ra- } \\
\text { ramente têm jornal impresso. }\end{array}$ & $\begin{array}{l}\text { Usa a internet para } \\
\text { trabalhar, de forma diária, } \\
\text { e também para lazer. }\end{array}$ \\
\hline Dina & 53 & $\begin{array}{l}6^{\circ} \text { ano; empre- } \\
\text { gada de limpeza }\end{array}$ & Internet; telemóvel & $\begin{array}{l}\text { Em casa há televisão e livros: } \\
\text { escolares, romances, livros } \\
\text { de arquitetura, a Bíblia e } \\
\text { outros livros religiosos. } \\
\text { Lê revistas informativas, } \\
\text { que recolhe quando faz } \\
\text { limpezas numa empresa } \\
\text { de transportes públicos. }\end{array}$ & $\begin{array}{l}\text { Não usa. Tem um telemóvel } \\
\text { antigo apenas para chama- } \\
\text { das, sobretudo dos filhos, } \\
\text { sem acesso à internet. }\end{array}$ \\
\hline Justina & 46 & $\begin{array}{l}9^{\circ} \text { ano; atualmen- } \\
\text { te desempregada }\end{array}$ & $\begin{array}{l}\text { "Notícias tristes"; } \\
\text { condicionamen- } \\
\text { tos económicos } \\
\text { também fazem } \\
\text { com que tenha de } \\
\text { gerir os gastos. }\end{array}$ & $\begin{array}{l}\text { Em casa há televisão, com- } \\
\text { putador (que pouco usa), } \\
\text { livros, CDs, bandas dese- } \\
\text { nhadas, filmes. Não compra } \\
\text { jornais. Usa a internet do } \\
\text { telemóvel, com autonomia. } \\
\text { Nota: a filha demarcou- } \\
\text {-se das referências a li- } \\
\text { vros feita pela mãe. }\end{array}$ & $\begin{array}{l}\text { Vê o jornal Correio da Ma- } \\
\text { nhã na internet. Usa no tele- } \\
\text { móvel de forma autónoma. }\end{array}$ \\
\hline
\end{tabular}




\begin{tabular}{|c|c|c|c|c|c|}
\hline Rita & 16 & $11^{\circ}$ ano; estudante & $\begin{array}{l}\text { Por motivos fami- } \\
\text { liares nem sempre } \\
\text { pode aceder à inter- } \\
\text { net e ao telemóvel. } \\
\text { Isso faz com que } \\
\text { quase se esque- } \\
\text { ça da existência } \\
\text { deles e adeque o } \\
\text { seu quotidiano a } \\
\text { esta escassez. }\end{array}$ & $\begin{array}{l}\text { Tem livros no seu quarto, } \\
\text { e lê muito. Em casa há } \\
\text { filmes, CDs e consola de } \\
\text { jogos, mas não há aces- } \\
\text { so à internet. A televisão } \\
\text { está em espaço comum. }\end{array}$ & $\begin{array}{l}\text { Não tem internet em casa, } \\
\text { usa na escola ou no café. }\end{array}$ \\
\hline Olavo & 17 & $9^{\circ}$ ano; estudante & $\begin{array}{l}\text { Por motivos } \\
\text { económicos, não } \\
\text { tem telemóvel. }\end{array}$ & $\begin{array}{l}\text { Em casa, tem televisão e } \\
\text { livros mas lê pouco; vê filmes, } \\
\text { sobretudo no tablet, que usa } \\
\text { para aceder à internet. O } \\
\text { telemóvel estragou-se e não } \\
\text { pôde comprar outro, diz que } \\
\text { se habituou a essa situação. }\end{array}$ & $\begin{array}{l}\text { Usa a internet no centro de } \\
\text { jovens, em casa usa num } \\
\text { tablet; não tem compu- } \\
\text { tador nem telemóvel. }\end{array}$ \\
\hline
\end{tabular}

Ressalta neste grupo composto sobretudo por adultos acima dos 45 anos a resistência apontada à internet em geral, à rede social Facebook em particular e a certos tipos de notícias ("notícias tristes", "notícias de política").

Em consonância com a literatura, pesam também o género e condições socioeconómicas e culturais: é sobretudo em mulheres e em contextos de carência económica e cultural que se encontram mais recusas à internet. Referindo ter "livros em casa", o televisor continua a ser o meio dominante, para entretenimento e informação. Há quem use a internet apenas por motivos profissionais, não a inserindo noutros contextos.

Os dois jovens que surgem nesta tabela não referem rejeição, mas sim constrangimentos a que se habituaram. Com um percurso escolar marcado por insucesso, Olavo refere escassa relação com a leitura e gosto em ver filmes no ecrã digital no seu tablet, num lar pouco apetrechado tecnologicamente. Rita, com um percurso escolar bem-sucedido, refere hábitos de leitura e meios digitais acessíveis aos membros do agregado, mas não pode usar internet em casa: os pais não compram acesso receando que o irmão reincida numa dependência online. Nos dois casos, o contexto familiar condiciona a escolha individual e a própria comunicação: ambos não quiseram que os pais participassem na pesquisa.

\section{RESISTÊNCIAS E RECUSAS DE PARES FAMILIARES}

Quando elementos de duas gerações coincidem em referir resistências vejamos se isso aponta transmissão familiar de uma dada cultura.

Dos cinco núcleos familiares da Tabela 2, dois são constituídos por famílias recompostas, circulando o elemento mais jovem por ambos os lares. A escolaridade dos adultos é superior à da Tabela 1, com vários profissionais diferenciados.

Encontramos aqui um claro foco no meio rejeitado. Três pares familiares recusam o Facebook e dois recusam a televisão. Nenhum par rejeita a internet em geral, apontando para a sua incorporação como meio. 
A recusa do Facebook pelos mais novos deixa os pais - que também não a usam - agradados e os jovens a sentirem-se fora do "rebanho" dos seus pares que seguem as redes sociais. No que respeita à televisão, a rejeição comporta núcleos familiares de nível educacional elevado e lares ricos em média (livros, internet, rádio, entre outros). A rejeição parte dos pais e é apropriada pelos filhos, na transmissão geracional de que falava Buchner (2003). Estes também se olham como alternativos face aos colegas.

\begin{tabular}{|c|c|c|c|c|c|}
\hline PARTICIPANTE & IDADE & $\begin{array}{l}\text { ESCOLARIDADE } \\
\text { E PROFISSÃo }\end{array}$ & $\begin{array}{l}\text { RESISTÊNCIA/ } \\
\text { REJEIÇÃO }\end{array}$ & $\begin{array}{l}\text { AMBIENTES MEDIÁTICOS } \\
\text { DE ACESSO A NOTÍCIAS }\end{array}$ & USOS DA INTERNET \\
\hline Susana & 54 & $\begin{array}{l}12^{\circ} \text { ano; trabalha } \\
\text { numa seguradora }\end{array}$ & Facebook; internet & \multirow{2}{*}{$\begin{array}{l}\text { Em casa há muitos livros, um } \\
\text { computador fixo e um telefone } \\
\text { “jurássico". Costumam ver as } \\
\text { notícias na televisão e usam a } \\
\text { box para ver e gravar filmes. }\end{array}$} & $\begin{array}{l}\text { Usa pouco a internet; } \\
\text { sobretudo no trabalho e } \\
\text { porque "tem de ser". }\end{array}$ \\
\hline António & 19 & $\begin{array}{l}12^{\circ} \text { ano; } \\
\text { estudante }\end{array}$ & Facebook & & $\begin{array}{l}\text { Usa internet, sobretudo } \\
\text { no computador em casa e } \\
\text { não tanto no telemóvel. }\end{array}$ \\
\hline Isabel & 49 & $\begin{array}{l}\text { Licenciatura; } \\
\text { enfermeira }\end{array}$ & Facebook & \multirow{2}{*}{$\begin{array}{l}\text { Além de televisão, há três } \\
\text { portáteis em casa, CDs, DVDs, } \\
\text { livros e banda desenhada. Há } \\
\text { também televisão e jornais. } \\
\text { A filha refere que gosta muito } \\
\text { de ler. A mãe diz que segue } \\
\text { as notícias pela internet. }\end{array}$} & $\begin{array}{l}\text { Acede à internet no telemóvel, } \\
\text { em casa e no trabalho, para } \\
\text { pesquisa profissional e pes- } \\
\text { soal, e para seguir as notícias. }\end{array}$ \\
\hline Sónia & 14 & $9^{\circ}$ ano; estudante & Facebook & & $\begin{array}{l}\text { Acede à internet no portátil } \\
\text { e no telemóvel. Usa mais } \\
\text { em casa do que na escola. }\end{array}$ \\
\hline João & 61 & $\begin{array}{l}\text { Licenciatura; } \\
\text { reformado (as- } \\
\text { sistente social) }\end{array}$ & Facebook; internet & $\begin{array}{l}\text { Em casa, além da televisão } \\
\text { e da rádio (sempre ligada), } \\
\text { há livros, CDs, DVDs, jogos } \\
\text { de tabuleiro. Antigamente, } \\
\text { comprava mais jornais e } \\
\text { revistas do que hoje, por ques- } \\
\text { tões financeiras. Considera- } \\
\text {-se informado e lê jornais } \\
\text { e revistas na biblioteca. }\end{array}$ & $\begin{array}{l}\text { Usa a internet sobretudo } \\
\text { em casa e na biblioteca; por } \\
\text { vezes usa no telemóvel. }\end{array}$ \\
\hline Rute & 14 & $9^{\circ}$ ano; estudante & Facebook & $\begin{array}{l}\text { Nas duas casas (paterna e } \\
\text { materna) tem bens culturais } \\
\text { semelhantes; na casa da mãe } \\
\text { tem revistas e na casa do pai } \\
\text { tem jogos de tabuleiro e banda } \\
\text { desenhada que aprecia pouco. }\end{array}$ & $\begin{array}{l}\text { Acede à internet em ambas } \\
\text { as casas, nos portáteis, no } \\
\text { telefone, e no tablet, o dis- } \\
\text { positivo que mais usa... Usa } \\
\text { muito o telemóvel sobretudo } \\
\text { para falar, pesquisar e jogar. }\end{array}$ \\
\hline Raquel & 46 & $\begin{array}{l}\text { Licenciatura; } \\
\text { engenheira }\end{array}$ & Televisão & $\begin{array}{l}\text { Em casa há rádio, muitos } \\
\text { livros, ("todos leem imen- } \\
\text { so, dão livros de prendas"), } \\
\text { assinam jornais e revistas } \\
\text { (incluindo estrangeiros e } \\
\text { específicos para crianças, } \\
\text { como Visão Júnior), bandas } \\
\text { desenhadas, revistas de moda. }\end{array}$ & $\begin{array}{l}\text { Acede frequentemente à inter- } \\
\text { net, em vários dispositivos. }\end{array}$ \\
\hline Marta & 14 & $9^{\circ}$ ano; estudante & Televisão & $\begin{array}{l}\text { Tem rádio, muitos livros, que } \\
\text { gosta de ler, tem muitos livros } \\
\text { no quarto. Em casa, há CDs, } \\
\text { filmes (antigos e novos). }\end{array}$ & $\begin{array}{l}\text { Usa Internet, no telefone, } \\
\text { no iPad e no computador. }\end{array}$ \\
\hline
\end{tabular}




\begin{tabular}{|c|c|c|c|c|c|}
\hline Miguel & 48 & $\begin{array}{l}\text { Doutoramen- } \\
\text { to; Químico }\end{array}$ & Televisão & $\begin{array}{l}\text { Em casa, há livros, bandas } \\
\text { desenhadas, já chegou a } \\
\text { comprar jornais e revistas, } \\
\text { mas por questões econó- } \\
\text { micas deixou de o fazer. }\end{array}$ & $\begin{array}{l}\text { Em casa acede à internet } \\
\text { com uma pen, no portá- } \\
\text { til (há muitos anos que } \\
\text { não tem computador) e } \\
\text { também no telemóvel. }\end{array}$ \\
\hline Helena & 17 & $\begin{array}{l}12^{\circ} \text { ano; } \\
\text { estudante }\end{array}$ & Televisão & $\begin{array}{l}\text { Em casa do pai lê muito. Em } \\
\text { casa da mãe lê, mas também } \\
\text { vê alguma televisão; por vezes, } \\
\text { ouve música e tem CDs. }\end{array}$ & $\begin{array}{l}\text { Na casa do pai acede à } \\
\text { internet numa pen, na } \\
\text { casa da mãe quando quer } \\
\text { é wireless e usa muitos os } \\
\text { dados móveis do telefone. }\end{array}$ \\
\hline
\end{tabular}

Tabela 2: Resistências e impossibilidades de pares familiares

\section{MOTIVOS DE RESISTÊNCIA OU DE IMPOSSIBILIDADE}

\section{NÃo GOSTO E NÃO QUERO USAR}

Neste grupo temático encontram-se adultos (quase todos mulheres e acima dos 45 anos) de diferentes níveis socioeconómicos e de escolaridade, que evocam o direito a ter opção na sociedade digitalizada, seguindo uma intencionalidade em recusar (Neves \& Rente, 2017). Se alguns têm de fazer uso da internet por motivos profissionais, para todos estar na internet é algo que rejeitam, porque não gostam ou não querem.

Estas resistências expressas com veemência, sobretudo por mulheres com baixos níveis de escolaridade e empregos indiferenciados, apesar de indicarem agência e voz, podem também fazer esconder a sua incapacidade em fazer uso da internet.

Dina, que completou o $6^{\circ}$ ano em adulta através do programa Novas Oportunidades, não usa a internet por opção. O telemóvel é também um dispositivo que recusa e de que se esquece. Autointitula-se de forma descontraída como "apagadinha". Recusa estar online, mesmo com os filhos a dizer que gostariam que estivesse e que a ajudariam. Contudo, procura estar informada. Ainda que acidentalmente, lê artigos sobre tecnologias (as suas vantagens para os jovens, os perigos que podem trazer e as suas capacidades em termos de sociedade do futuro), que saem na revista Visão, que recolhe no local onde faz limpezas. Gosta de ler sobre o assunto para poder acompanhar e falar com os filhos, mas recusa o apoio técnico que eles lhe poderiam proporcionar.

Entrevistadora: Em que condições acede a computadores, ao telemóvel, à internet?

Dina: Completamente apagada. Apagada! Apagadinha!

E: Não tem telemóvel?

D: É assim, tenho telemóvel, o mais simples dos simples e mesmo assim, eu só consigo fazer chamadas e às vezes abro mensagens que me mandam, mas é preciso que a mensagem entre e eu oiça e veja. Porque senão não ligo. Não. (...) É uma opção minha. Não só, tenho mesmo dificuldade, não me esforço para melhor...

E: Por exemplo, e se os seus filhos a ajudassem nessa tarefa?

D: Sempre tentam ajudar, mas eu ponho sempre outras coisas... (Dina, 53) 
Arminda, por sua vez, vê com desagrado a imposição de ter de usar a internet e os emails na sua atividade profissional.

Entrevistadora - Onde e em que condições acede a computador e internet? Arminda - Só, exclusivamente e porque fui obrigada, sou adversa às tecnologias nessa área, e estamos a falar até há cerca de dois anos, até lá reneguei qualquer computador na empresa. Tudo o que seja área de computadores, posso dizer-lhe que tenho telemóvel da empresa para atender e fazer chamadas [não manda mensagens], não quero saber de mais nada. Só uso computador para trabalho da empresa e $90 \%$ é para ler e escrever emails. Não quero ir ao Google, não quero nada, não me faz mais feliz, graças a Deus. (Arminda, 59 anos)

Entre os dois entrevistados que vivem em ambientes mediáticos ricos, ela rejeita a internet de modo radical, ele recusa o uso exagerado. Já reformado de assistente social, João (61 anos) interessa-se por notícias e incentiva a filha nas atividades relacionadas com a leitura e com o uso da internet; ele próprio a usa para busca de informação que Ihe interessa, mas tem outras prioridades na vida. Saiu mesmo das redes sociais por as considerar uma perda de tempo.

Reformei-me e liguei-me ao Facebook, mas quando vi que estava a perder imensas horas naquilo, deixei. A vida não é isto. Quando tenho um interesse vou procurar seja na biblioteca ou online. Por exemplo há uns dias uma amiga emprestou-me um livro de uma senhora chamada Chimamanda Adichie, é uma coisa impressionante, fiquei tão fascinado, que fui procurar [à internet], queria saber mais. Em termos utilitários é muito direcionado. $\mathrm{O}$ meu trabalho prioritário é a minha filha. (João, 61 anos)

Em comparação com a televisão e a rádio, em especial entre os adultos mais veIhos, a internet é tida como secundária no que se refere ao uso próprio. O mesmo já não acontece quando se referem a filhos e netos. Todos consideram que a internet é uma ferramenta importante para os mais jovens e para os seus filhos, em particular. Como membros pouco qualificados da sua geração, colocam-se de fora mas pretendem a integração digital dos seus descendentes.

Não, quer dizer, internet não. Eu tenho internet porque tenho televisão e tenho... é assim, eu tenho internet porque tenho telefone... Mas se eu não pagar, se me cortarem a internet, não faz falta. E se me cortarem a água ou a luz faz-me falta. Por isso é que essencial, essencial é mais a água e a luz. A internet já não... é secundário. Quer dizer é secundário para mim, agora faz falta é para ele [neto]. (Antónia, 49 anos) 


\section{NESTA FASE DA VIDA, NÃO!}

Neste grupo, indivíduos adultos com diferente escolaridade rejeitaram notícias específicas que lhes desagradavam, ou por serem tristes ou por se relacionarem com política, traduzindo desconforto ou desencanto. O modo como exprimiram essa rejeição traduz-se numa tomada de posição que justificam pela fase da vida em que se encontram.

Duas mulheres, que declararam ter passado a estar mais atentas à informação quando se tornaram mães, recusam-se agora a estar a par de notícias que as entristecem, ou que podem entristecer as filhas, com as quais vivem como famílias monoparentais. O não seguimento das notícias parece ser agora uma estratégia de casulo.

Outro fator que pode contribuir para esta recusa é o desinteresse, mesmo que pontual, por temas como a atualidade política (Brites, 2015). Um dos pais, Romeu, com doutoramento e a exercer funções de direção em instituição de ensino superior, referiu limitações decorrentes da sua decisão de não seguir nem notícias (uma opção gerada pelo seu desapontamento face à situação política) nem a rede Facebook (fica excluído/ impedido de divulgar ele mesmo as atividades enquanto diretor e artista).

Entre os motivos para rejeições de notícias estão: serem demasiado negativas, ponto referido em especial por mulheres com vidas duras, na linha do que foi encontrado por Helgerud (2017), Moeller (1999), Newman et al. (2017), Schrøder e BlachØrsten, 2016; o seu descrédito (Newman et al., 2017); o desencanto com a política (Brites, 2015).

Arminda: Sou capaz de dizer basta [às notícias que a deixam triste], recuso-me a ver notícias só porque sim, porque tenho de ter pena, ver a criança na praia, por isso, não. Eu não posso mudar o mundo, porque hei de sentir-me mal, se quem pode mudar não faz nada? Atualmente não há uma seleção e qualquer pessoa de qualquer idade vê, sem aviso, até crianças, eu rejeito isso. Acho que devia ser direcionado, mas se calhar que eles dizem que a notícia é chocante, mas isso até aguça. (...) Entrevistadora: Se as notícias fossem mais positivas? A: Positivas, mas sem desviar do que existe. Na realidade vivemos num mundo de confusões. Mas eu tenho direito a querer sentir-me bem. (Arminda, 59 anos)

Não estamos perante uma visão fatalista, mas perante uma opção deliberada e intencionada de quem se habituou a fazer escolhas em contracorrente à sociedade em que vive: Arminda considera-se uma pessoa informada e uma mulher lutadora. Falou amplamente do seu papel enquanto mulher fragilizada antes do 25 de Abril e de emancipada depois, da luta pela dignidade no trabalho e da superação da morte recente do marido. Apesar de evitar notícias negativas, disse que se interessa por informação no dia a dia e que gosta de conversar com a filha sobre temas de atualidade. 


\section{ENTRE O NÃO POSSO COMPRAR E NÃO POSSO TER}

Este grupo é composto por pessoas de baixos recursos económicos e por escoIhas familiares em que não há espaço de diálogo sobre usos dos média e de procura de soluções conjuntas. Todos adaptam a sua vida quotidiana às limitações que enfrentam. As implicações acabam por se entranhar e criar rotinas de resistência e de contorno do uso de certos média. São os constrangimentos estruturais, externos a si mesmos, que afetam o que poderiam ter.

A dimensão dos custos foi indicada por Olavo, 17 anos, sem telemóvel por o seu se ter estragado e não ter possibilidade para comprar outro. Constrangimentos verificam-se também em situações onde razões económicas são indicadas em termos mais gerais, como Justina, desempregada e a viver de subsídios.

A exceção a esta descrição marcada pela carência económica é de uma jovem, Rita, sem internet em casa, o que faz com que tenha de a usar em cafés e na escola. Rita faz uma gestão cuidada do que tem de fazer (pesquisas pessoais, trabalhos de casa, contactos de email) e controla os tempos que tem para estar online. Quase por arrasto, evita também o telemóvel, que já não considera essencial no seu dia a dia. Muito ativa na escola, onde lidera atividades como a rádio escolar, não se demite de participar apenas porque tem um acesso limitado à internet.

Entrevistadora: Onde e em que condições acedes a computador e internet?

Rita: Não tenho net em casa, porque os meus pais não querem dar-me. Mas normalmente uso nos computadores aqui na escola ou quando trago o iPad.

Às vezes por causa da rádio.

E: E no telemóvel?

R: O telemóvel não serve para nada. Está sempre parado. Sem bateria. Tenho, mas não uso. E também a internet no tablet quando vou ao café.

E: E acesso ao computador?

R: Tenho computador em casa, um portátil, e quando tenho tra-

balhos que preciso de internet, ou recolho a informação aqui

na escola ou vou ao café uma tarde e faço tudo o que preci-

so. E depois faço o trabalho em casa. (Rita, 16 anos)

A dada altura, Rita considerou que esta opção familiar poderia constituir uma violação dos seus direitos humanos - a relação da internet com direitos era uma das partes temáticas do guião de entrevista - e estabeleceu o contexto com a sua vida pessoal. Apesar dessa reflexão, não deixou de vincar o seu posicionamento no uso desse recurso:

honestamente, se eu fosse uma pessoa revoltada com os meus pais porque eles não me dão internet, era capaz de chegar a casa e usar essa informação contra eles! E ainda sou capaz de lhes dizer. Mas para mim a internet... eu vivo bem sem, não tenho a necessidade extrema de ter internet. (Rita, 16 anos) 


\section{NÃo DAR NAS VISTAS E NÃO FICAR “AGARRADo”}

Entrevistados jovens e adultos (alguns membros da mesma família, neste caso, ver Tabela 2) mostraram a sua rejeição à exposição pública e à possibilidade de se ligarem de forma exagerada a um meio, o Facebook. Rejeitam a rede social para manterem controlo sobre as suas vidas pessoais e evitarem a exposição pessoal. Na sua reflexão há recusa do que já conhecem e que criticam na forma como está concebida, há uma estratégia de autorregulação para evitar que os média se transformem em algo demasiado invasivo (Syvertsen, 2017, p. 98).

Tenho recusado o Facebook, já participei numa rede, o MySpace. (...) mas há pouco tempo saí, porque para pertencer a uma rede social implica que vá lá com alguma assiduidade, e já tenho tantas coisas, não queria mais uma. Perturba-me ter que estar a lidar com esta obrigatoriedade... (Romeu, 47 anos)

O telemóvel está ligado, mas não tenho Facebook. Sinto isto até por causa dos filhos, porque estão sempre com isto, os 'faces', etc. Tento combater isso lá em casa, como nas horas das refeições a ver se há partilha, diálogo, de contrário... é uma invasão do nosso espaço. (Filipe, 45 anos)

Nos casos em que há uma rejeição do Facebook pelos jovens, ainda que não imposta pelos pais, estes manifestam alívio pela opção semelhante dos mais novos. Os mais adultos fazem questão de indicar que não tiveram influência sobre a decisão dos filhos de rejeitarem o Facebook. Nos mais novos, a devassa da vida privada é apontada como fator de rejeição desta rede social, como se nota neste par familiar.

Não é coisa assim que me desperte muito... As redes sociais. Às minhas filhas também não e olhe e não foi nunca porque eu dissesse "Não têm, não podem ter...". Não, nunca foi nada disso. A mais velha já acho que teve Facebook, e depois chegou à conclusão que... que aquilo era uma treta, que as pessoas expunham a vida delas... Não tinha interesse nenhum. (Isabel 49 anos)

Eu acho que o conceito até poderia não ser muito mau [o Facebook], mas, entretanto, as pessoas, como é que eu hei-de dizer? Principalmente na minha idade têm tornado o site assim um bocado... só serve para falar da vida delas, fotos assim... eu não gosto. (Sónia, 14 anos)

Todos os entrevistados que rejeitaram o Facebook consideraram as implicações pessoais, sociais e até profissionais de estarem fora de um espaço onde os amigos, os colegas e os filhos se "encontram" - ou "desencontram" como preferiam identificar. Percecionam que quem está na rede os tenta captar no sentido de poderem partilhar mais e contactar mais. Estas recusas implicam também uma opção de estar fora do padrão, 
de estar à margem. É o caso do António, que chegou a estar muito viciado na internet e nas redes, mas que hoje se recusa a fazer parte do Facebook.

António: Não me importo [de não usar Facebook]. Já me chegaram a dizer que não tinha Facebook e assim coisas, mas eu vou-lhe dizer a verdade, isso não me preocupa.

Entrevistadora: Não ligas?

A: Não, estou-me nas tintas para isso. (António, 19 anos)

\section{FAZER DIFERENTE E FAZER MELHOR}

Neste grupo, a resistência à televisão está ligada a uma recusa efetiva e opção consciente de elementos com fortes preocupações culturais, evidenciando a expressividade das microculturas familiares (Buchner, 2003). Podem possuir esse aparelho mas rejeitam o seu uso com o argumento de assim poderem conversar mais em família ou realizarem interesses culturais que seriam difíceis de concretizar se o quotidiano fosse pautado pelo televisor.

São ambientes familiares ricos em média, em livros e em diferentes formas de cultura incluindo o interesse por acompanhar a atualidade política (ver Tabela 2). Esta recusa, que parte dos adultos da família, é seguida pelos mais novos.

Não são opções lineares nem coincidentes. Na família 1, a mãe Raquel e o marido questionam-se com frequência sobre se não ver televisão, nomeadamente as notícias, é a melhor forma de assegurar uma educação mais rica cultural e civicamente, em especial perante questões relevantes, como a crise económica e atentados terroristas. $\mathrm{Na}$ família 2, recomposta, as filhas não têm televisão na semana em que estão a viver com o pai. Miguel não se questiona sobre as vantagens de não ter televisão, e Helena, a filha, também está satisfeita com a opção. Quando usa a televisão na casa da mãe é para ver notícias - sendo muito crítica das opções noticiosas da televisão - e gosta de debater questões políticas com o pai.

Família 1:

Isso [não usar televisão] tem um senão, não são só vantagens, por exemplo quando foi da questão dos refugiados, toda a gente falava do assunto e as minhas filhas estavam longe. (...) Como nós acabamos por não ver televisão, há ali uma lacuna. (...) pela internet tem de haver alguma disciplina, não? Pela televisão àquela hora dá notícias, na internet tem de haver mais disciplina na procura. Tenho tantas solicitações na minha agenda que não sei se quero marcar uma hora diária para ir ver notícias. [ri-se]. (Raquel, 46 anos)

Marta: Eu já tive televisão. Quer dizer, tive uma televisão em casa, mas só tinha os quatro canais, e só tive os canais todos quando andava para aí no 
segundo ano, ou... primeiro, segundo ano, já não tenho bem a certeza.

Entrevistadora: Quem optou por não ter televisão? Imagino que talvez tenham sido os teus pais...

M: Eu não sei. Acho que nós... Eu lembro-me quando fo-

ram lá instalar a televisão... nós tínhamos mudado de casa há

cerca de dois anos e... [acharam que não tinham espaço para

a televisão e optaram por deixar de ver]. (Marta, 14 anos)

Família 2:

A única coisa que... a única coisa que me fez pensar por algum tempo foi as coisas boas que a televisão tem, sobretudo o cabo. E, portanto, mas e há um canal pelo menos, a TV2 na nossa televisão de sinal aberto, na nossa televisão pública que passa algum conteúdo com qualidade. Tudo o resto para mim é muito limitado, muito e que não justifica a existência de uma televisão em casa. Portanto, nunca receei esse... As minhas filhas são perfeitamente informadas, não perdem nada, acho que só se ganha em não ter televisão. (Miguel, 48 anos)

Quando vejo notícias na televisão, especialmente os canais portugueses [na casa materna ou programas na internet e com escolha pessoal], acho que é muito direcionado a um tipo de sensação que eles querem gerar em nós, por exemplo, aquele caso de Paris, achei um bocado ridículo... durante semanas passou sempre Paris, Paris, Paris e depois as pessoas que não têm a sorte ou não têm, sei lá, oportunidade de pesquisar e ouvir de outras fontes pensam que só aconteceu isso. E não sabem de outros ataques ou de outras coisas que se estão a passar que não é só na Europa, isso não é só centrado no nosso mundinho. Pronto, nesse sentido, consumo isso. A nível de internet e de plataformas virtuais, vejo... na internet vejo notícias a nível do que se está a passar, lá está, a nível social, no mundo, não tão político, mais direitos humanos, tudo isso. (Helena, 17 anos)

Tanto por parte dos adultos como das jovens, esta recusa da televisão configura-se positiva. Há pais preocupados pelo que se perde de sociabilização, pois os colegas na escola conversam sobre notícias que cumprem o agendamento determinado pela televisão. Já os mais jovens sentem-se especiais, e são assim que são vistos pelos colegas. Uma das raparigas da família 2 é vista pelos colegas como a mais culta da turma.

\section{Conclusões}

Assinalando a natureza profundamente mediatizada das sociedades contemporâneas e tendo em conta particularidades do contexto português, este estudo exploratório analisou os modos como 18 entrevistados, incluindo pares familiares compostos por 
membros de diferentes gerações, mostraram sinais de resistência e ou de impossibilidade em usufruir dos média. Nuns casos, os sinais incidiram na internet e vieram apenas de um dos membros da família, quase sempre da geração mais velha, mulheres e com baixa escolaridade, reproduzindo um padrão já identificado (Ponte, 2011). Noutros, pais e filhos evidenciaram práticas comuns de rejeição da rede social hegemónica, o Facebook, de indiferença para com a televisão e de interesse comum em procurar alternativas para estar informado e usufruir do entretenimento mediático.

Assim, não se deu conta de uma rejeição global dos média mas de resistências e de constrangimentos, manifestando-se de diferentes modos e podendo ser singulares ou plurais. Essa resistência esbarra com contextos profissionais onde não se pode deixar de usar, mesmo não querendo.

As duas expressões, não querer e não poder, apontam para intencionalidades distintas, mas igualmente consequentes. A falta de capital cultural (Bourdieu, 2003) pode levar ao receio de usar, e assim evidencia um não poder por falta de competências. São ainda notórios o cansaço e o desencanto relacionados com uma determinada fase da vida ou condição económica da vida, e uma vontade em afirmar uma diferença social. A resistência a um certo tipo de informação noticiosa foi mais expressa por pais e mães do que associada a um certo desejo de ignorar o que não consideram estar ao seu alcance mudar. Entre os mais jovens e de famílias com mais recursos, a apetência pela informação é claramente incentivada pelo ambiente familiar mas pode ser também incentivada por dinâmicas de participação cívica em contexto escolar (Brites, 2015).

Dinâmicas geracionais são evidentes tanto em situações em que se denota a rejeição ao uso da internet, por parte dos adultos, mesmo com o incentivo dos mais novos - que aqui subvertem os tradicionais processos de transmissão - como nos pares familiares onde os hábitos dos mais novos claramente decorrem do ambiente em que cresceram - como é o caso da indiferença face à televisão.

Importa ainda anotar as tomadas de decisão que decorrem de um balanço a uma experiência anterior, como abandonar uma rede social. Diríamos que é preciso imprimir esforço para que se leve avante uma resistência ou rejeição àquilo que constitui o padrão dominante nas práticas com os média. No que respeita às redes sociais, foi prevalente uma consciência do direito a ter opção na sociedade digitalizada. Quando se afirma a pressão para se estar na rede social onde estão todos os internautas portugueses, não deixa de ser sintomático deste esforço que seja a rede social Facebook o meio que recolheu maior número de referências.

Além das motivações de sentido positivo, anotamos outras de entendimento mais negativo, como que de subjugação. São resistências e rejeições por consequência de fatores de ordem estrutural (imposição familiar) e situação socioeconómica (exclusão clássica). Nestes casos, houve uma estratégia de adaptação à limitação existente de uso dos média.

Estes resultados indicam que saber optar requer capacidades que nem sempre são facilitadas. Se este aspeto tem sido desenvolvido face ao consumo, também podemos dizer que recusar e rejeitar depende de vários fatores, como recursos culturais 
e competências mediáticas para a escolha crítica e consciente, numa sociedade regida pela voragem dos média.

\section{Agradecimentos}

Este trabalho foi financiado através da Fundação da Ciência e da Tecnologia (SFRH/ $\mathrm{BPD} / 92204 / 2013)$. Este trabalho é financiado por fundos nacionais através da FCT Fundação para a Ciência e a Tecnologia, I.P., no âmbito do projeto UID/CCl/4667/2016; e por Fundos Nacionais através da FCT - Fundação para a Ciência e a Tecnologia no âmbito do projeto com a Ref. ${ }^{a}$ UID/CCI/04667/2016 - Centro de Investigação em Comunicação, Informação e Cultura Digital.

\section{REFERÊNCIAS}

Amado, J., Costa, A. P. \& Crsoé, N. (2014). A técnica da análise de conteúdo. In J. Amado (Ed.), Manual de investigação qualitativa em educação (pp. 301-350). Coimbra: Imprensa Universidade de Coimbra.

Araújo, E., Cogo, D. \& Pinto, M. (2015). Mobilidades, media(ções) e cultura. Comunicação e Sociedade, 28, 7-14. DOI: $10.17231 /$ comsoc.28(2015).2267

Attride-Stirling, J. (2001). Thematic networks: an analytic tool for qualitative research. Qualitative Research, 1(3), 385-405. DOI: 10.1177/146879410100100307

Bardin, L. (2009). Análise de conteúdo. Lisboa: Edições 70.

Beck, U. (1997). Democratization of the family. Childhood, 4(2), 151-168. DOI: 10.1177/0907568297004002002

Beck, U. \& Beck-Gernsheim, E. (2002). Individualization: institutionalized individualism and its social and political consequences. Londres, Thousand Oaks e Nova Deli: Sage.

Bourdieu, P. (2003). Questões de Sociologia. Lisboa: Fim de Século.

Brites, M. J. (2015). Jovens e culturas cívicas: por entre formas de consumo noticioso e de participação. Covilhã: LabCom Books.

Buchner, P. (2003). The transmission of social and cultural capital between family generations. In B. Mayall \& $\mathrm{H}$. Zeiher (Eds.), Childhood in generational perspective (pp. 71-85). Londres: Institute of Education.

Burnay, C. e Ribeiro, N. (2016). As novas dinâmicas do consumo audiovisual em Portugal. Lisboa: ERC.

Castells, M. (2008). The new public sphere: global civil society, communication networks, and global governance. The ANNALS of the American Academy of Political and Social Science, 616(1), 78-93. DOI: $10.1177 / 0002716207311877$

Corbin, J. \& Strauss, A. (1990). Grounded theory research: procedures, canons, and evaluative criteria. Qualitative Sociology, 13(3), 3-21. DOI: 10.1007/BFoog88593

Couldry, N. \& Hepp, A. (2017). The mediated construction of reality. Cambridge, USA: Polity Press.

Dijck, J. v. (2013). The culture of connectivity: a critical history of social media. Oxford: Oxford University Press.

Elias, N. (1987). A sociedade dos indivíduos. Lisboa: Publicações D. Quixote. 
Helgerud, A. (2017). Sjeldenkonsumenter av nyheter: holdning til nyhetsmedier, medborgerskap og forklaringer på sjeldenkonsum blant unge voksne. Norsk medietidsskrift, 24(2), 1-19. DOI: 10.18261/ ISSN.0805-9535-2017-02-04

Hepp, A. \& Hasebrink, U. (2018). Researching transforming communications in times of deep mediatization: A figurational aproach. In A. Hepp, A. Breiter, \& U. Hasebrink (Eds.), Communicative figurations: transforming communications in times of deep mediatization (pp. 15-50). Gewerbestrasse: Palgrave.

Jenkins, H. (2006). Convergence culture: where old and new media collide. Nova lorque: New York University Press.

INE. (2015). Sociedade da Informação e do Conhecimento - inquérito à utilização de tecnologias da informação e da comunicação nas famílias: a participação em redes sociais é mais frequente em Portugal do que na EU. Retirado de http://smi.ine.pt/SuporteRecolha/Detalhes/?id=10246\&lang=PT

Krotz, F. (2009). Mediatization: a concept with which to grasp media and societal change. In K. Lundby (Ed.), Mediatization: concepts, changes and consequences (pp. 24-40). Nova lorque: Peter Lang.

Livingstone, S. (2014). The mediatization of childhood and education: reflections on the class.... In L. Kramp, N. Carpentier, A. Hepp, I. T. Trivundža, H. Nieminen, R. Kunelius, T. Olsson, E. Sundin, \& R. Kilborn (Eds.), Media practice and everyday agency in Europe (pp. 55-68). Bremen: Edition Lumière.

Milner, H. (2002). Civic literacy: how informed citizens make democracy work. Hanover e Londres: Tufts University.

Moeller, S. D. (1999). Compassion fatigue: how the media sell disease, famine, war and death. Nova lorque e Londres: Routledge.

Neves, B. B. \& Rente, R. (2017). Não alinhados? Jovens não utilizadores de sites de redes sociais. Sociologia Problemas e Práticas, 85, 107-129. DOI: 10.7458/SPP2017856943

Newman, N., Fletcher, R., Kalogeropoulos, A., Levy, D. A. L. \& Nielsen, R. K. (2017). Reuters Institute digital news report 2017. Retirado de https://tinyurl.com/yarldolr

Obercom (2017). Reuters Institute - digital news report 2017 Portugal. Retirado de https://obercom.pt/wpcontent/uploads/2017/12/2017-Reuters-Institute-DNR-PT.pdf

Ponte, C. (2011). Uma geração digital? A influência familiar na experiência mediática de adolescentes. Sociologia - Problemas e Práticas, 65, 31-50. Retirado de http://www.scielo.gpeari.mctes.pt/pdf/spp/n65/ n65ao2.pdf

Postman, N. (1985/2005). Amusing ourselves to death. Londres: Penguin Books.

Putnam, R. D. (2000). Bowling alone: the colapse adn revival of American community. Nova lorque: Simon \& Schuster.

Schrøder, K. C. \& BlachØrsten, M. (2016). The nature of news avoidance in a digital world-digital news report 2016. Retirado de http://www.digitalnewsreport.org/essays/2016/nature-news-avoidance-digital-world/

Seale, C. (2004). Generating grounded theory. In C. Seale (Ed.), Researching society and culture. Los Angeles, Londres, Nova Deli e Singapura: SAGE.

Syvertsen, T. (2017). Media resistance: protest, dislike, abstention. Gewerbestrasse: Palgrave.

Woodstock, L. (2014). Media resistance: opportunities for practice theory and new media research. International Journal of Communication, 8(2014), 1983-2001. Retirado de https://ijoc.org/index.php/ijoc/ article/view/2415 


\section{NOTAS BIOGRÁFICAS}

Maria José Brites é Professora associada na Faculdade de Comunicação, Arquitetura, Artes e Tecnologias da Informação, na Universidade Lusófona do Porto.

ORCID: https://orcid.org/0000-0002-9840-9554

Email: britesmariajose@gmail.com

Morada: Rua Augusto Rosa, n² 24, 4000-098 Porto-Portugal

Cristina Ponte é Professora associada com agregação no Departamento de Ciências da Comunicação da Faculdade de Ciências Sociais e Humanas da Universidade NOVA de Lisboa (NOVA FCSH)

ORCID: https://orcid.org/0000-0002-1534-4784

Email: cristina.ponte@fcsh.unl.pt

Morada: Av. De Berna, 26-C, 1069-061 Lisboa-Portugal

* Submetido: 12.04.2018

* Aceite: 23.07.2018 